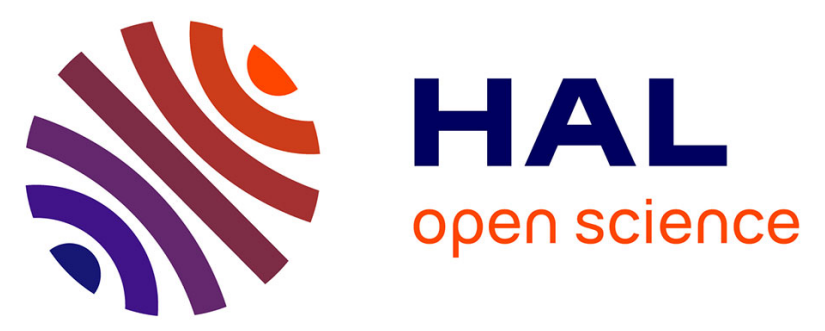

\title{
Construction of a synthetic metabolic pathway for the production of 2,4-dihydroxybutyric acid from homoserine
}

\author{
Thomas Walther, Florence Calvayrac, Yoann Malbert, Ceren Alkim, \\ Clémentine Dressaire, Hélène Cordier, Jean Marie François
}

\section{To cite this version:}

Thomas Walther, Florence Calvayrac, Yoann Malbert, Ceren Alkim, Clémentine Dressaire, et al.. Construction of a synthetic metabolic pathway for the production of 2,4-dihydroxybutyric acid from homoserine. Metabolic Engineering, 2018, 10.1016/j.ymben.2017.12.005 . hal-01886438

\section{HAL Id: hal-01886438 \\ https://hal.science/hal-01886438}

Submitted on 27 May 2020

HAL is a multi-disciplinary open access archive for the deposit and dissemination of scientific research documents, whether they are published or not. The documents may come from teaching and research institutions in France or abroad, or from public or private research centers.
L'archive ouverte pluridisciplinaire HAL, est destinée au dépôt et à la diffusion de documents scientifiques de niveau recherche, publiés ou non, émanant des établissements d'enseignement et de recherche français ou étrangers, des laboratoires publics ou privés. 


\section{Author's Accepted Manuscript}

Construction of a synthetic metabolic pathway for the production of 2,4-dihydroxybutyric acid from homoserine

Thomas Walther, Florence Calvayrac, Yoann Malbert, Ceren Alkim, Clémentine Dressaire, Hélène Cordier, Jean Marie François

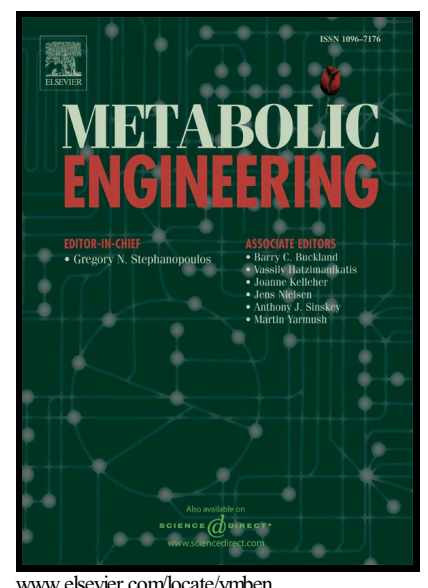

PII: S1096-7176(17)30350-6

DOI: $\quad$ https://doi.org/10.1016/j.ymben.2017.12.005

Reference: YMBEN1330

To appear in: Metabolic Engineering

Received date: 14 September 2017

Revised date: 6 December 2017

Accepted date: 7 December 2017

Cite this article as: Thomas Walther, Florence Calvayrac, Yoann Malbert, Ceren Alkim, Clémentine Dressaire, Hélène Cordier and Jean Marie François, Construction of a synthetic metabolic pathway for the production of 2,4dihydroxybutyric acid from homoserine, Metabolic Engineering, https://doi.org/10.1016/j.ymben.2017.12.005

This is a PDF file of an unedited manuscript that has been accepted for publication. As a service to our customers we are providing this early version of the manuscript. The manuscript will undergo copyediting, typesetting, and review of the resulting galley proof before it is published in its final citable form. Please note that during the production process errors may be discovered which could affect the content, and all legal disclaimers that apply to the journal pertain. 


\title{
Construction of a synthetic metabolic pathway for the
}

\section{production of 2,4-dihydroxybutyric acid from homoserine}

Thomas Walther ${ }^{1,2^{*} \#}$, Florence Calvayrac ${ }^{1,2}$, Yoann Malbert ${ }^{1,2}$, Ceren Alkim ${ }^{1,2}$, Clémentine Dressaire $^{1,2}$, Hélène Cordier ${ }^{1,2}$, Jean Marie François ${ }^{1,2^{*}}$

\begin{abstract}
Affiliations
${ }^{1}$ LISBP, Université de Toulouse, CNRS, INRA, INSA, Toulouse, France, 135 Avenue de Rangueil, F31077 Toulouse, France;

${ }^{2}$ TWB, 3 rue Ariane, 31520 Ramonville-St. Agne, France;

\# Present address: Institute of Natural Materials Technology, TU Dresden, 01062 Dresden, Germany
\end{abstract}

*Corresponding authors.

\section{E-mail adresses:}

thomas_walther@tu-dresden.de

fran_jm@insa-toulouse.fr 


\section{ACCEPTED MANUSCRIPT}

\section{Abstract}

2,4-dihydroxybutyrate (DHB) is a precursor for the chemical synthesis of the methionine analogue 2-hydroxy-4-(methylthio)butyrate. Since no annotated metabolic pathway exists for its microbial production from sugar, we have conceived a two-step synthetic metabolic pathway which converts the natural amino acid homoserine to DHB. The pathway proceeds through the homoserine transaminase-catalyzed deamination of homoserine to obtain 2-oxo-4-hydroxybutyrate (OHB), and continues with the reduction of OHB to DHB, which is catalyzed by an OHB reductase enzyme. We identified homoserine transaminase and OHB reductase activity in several candidate enzymes which act on sterically cognate substrates, and improved OHB reductase activity of lactate dehydrogenase A of Lactococcus lactis by structure-based enzyme engineering. Fed-batch cultivation of a homoserine-overproducing Escherichia coli strain which expressed homoserine transaminase and OHB reductase enzymes resulted in the production of $5.3 \mathrm{~g} / \mathrm{LDHB}$ at a yield of $0.1 \mathrm{~g} / \mathrm{g}$. 


\section{ACCEPTED MANUSCRIPT}

\section{Introduction}

The sulfur-containing essential amino acid (L)-methionine and its analogue 2-hydroxy-4(methylthio)butyrate (HMTB) are important supplements in poultry diets (Dilger and Baker, 2007; Sauer et al., 2008). The cumulated annual production volume of both compounds reached $\sim 1$ million tons in 2014 ("Feedinfo News Service" ). While most of the 20 proteinogenic amino acids are produced by fermentation processes from renewable sugar, the production of methionine and HMTB is still dominated by petroleum-based syntheses (Faurie et al., 2003; Leuchtenberger et al., 2005; Willke, 2014). This is mainly due to the very high metabolic cost of incorporating sulfur which requires the NADPH-dependent reduction of the standard sulfur source sulfate to sulfide (Krömer et al., 2006). Comparatively low methionine yields of microbial fermentations in combination with the fact that chemically produced racemic (D/L)-methionine has a very similar nutritional value as the pure (L)-enantiomer (Dilger and Baker, 2007) renders methionine fermentation processes at present uncompetitive with chemical production.

Producing methionine or HMTB by using more reduced sulfur sources, or via two-stage processes, where first a functionalized precursor is produced by fermentation and sulfur is subsequently incorporated by (bio)chemical means, is therefore a promising alternative. For example, (Zelder et al., 2009) have shown that methionine yields can be increased in microbial fermentations using engineered Corynebacterium glutamicum when the less oxidized dimethyl disulfide is used to replace sulfate as the sulfur source. In addition, an elegant two-stage industrial production process for (L)-methionine was recently developed in which the precursors Oacetylhomoserine or O-succinyl-homoserine are produced by optimized microorganisms through the fermentation of sugars (Hong et al., 2014; Shim et al., 2016). These precursors are then reacted with methanethiol in an enzymatic process stage to yield methionine. It was proposed that acetate or succinate, which is released during the enzymatic conversion of the precursor, can be recycled as substrate or be commercialized (Shim et al., 2016). 
An alternative approach was recently proposed by our group and consists in the production of 2,4-dihydroxybutyrate (DHB) by microbial fermentation of sugar (Walther et al., 2017), and the subsequent chemical conversion of DHB and methanethiol to HMTB. The chemical process stage has near $100 \%$ product yield (Deck et al., 2009) and does not produce any by-products, which may simplify process design and reduce manufacturing costs.

Annotated natural DHB-producing metabolic pathways do not exist. Reports on the occurrence of DHB in natural organisms are limited to a study on human patients suffering from succinic semialdehyde dehydrogenase deficiency, where the accumulation of trace amounts of DHB in the patient's urine was observed without revealing the underlying metabolic pathway responsible for DHB production (Shinka et al., 2002). Therefore, we have recently developed a three-step synthetic metabolic pathway which converts the natural precursor malate into DHB via the activation of malate by phosphorylation followed by two successive reduction steps (Walther et al., 2017). The pathway employs previously unknown malate kinase, malate semialdehyde dehydrogenase, and malate semialdehyde reductase enzymatic activities which were obtained by semi-rational engineering of template enzymes which act on sterically cognate substrates. An engineered Escherichia coli strain which simultaneously expressed the optimized enzymes and the anaplerotic enzyme phosphoenolpyruvate carboxylase produced $1.8 \mathrm{~g} / \mathrm{L}$ DHB from $20 \mathrm{~g} / \mathrm{L}$ glucose in shake flaks (Walther et al., 2017). In addition, Li et al. (2014) and our group (Walther et al., 2013) have constructed an alternative three-step synthetic pathway which converts malate to DHB via the characteristic intermediate malyl-CoA. This pathway, however, was so far reported to yield only trace amounts of DHB (<10 mg/L).

In the present work we describe the design and construction of a two-step synthetic metabolic pathway which converts the natural precursor homoserine into DHB. The pathway relies on the homoserine transaminase-catalyzed deamination of homoserine to produce 2-oxo-4- 


\section{ACCEPTED MANUSCRIPT}

hydroxybutyrate $(\mathrm{OHB})$, and the subsequent reduction of $\mathrm{OHB}$ to $\mathrm{DHB}$, which is catalyzed by an $\mathrm{OHB}$ reductase. Although other aminotransferase-reductase pathways appear to exist in natural organisms, as indicated by the serine-to-glycerate pathway which may operate in mice (Hagopian et al., 2005; Snell, 1986), we found no report on the operation of the homoserine-to-DHB pathway in natural organisms. Our work showed that several natural candidate transaminase and 2-hydroxyacid dehydrogenases had significant homoserine transaminase and OHB reductase activity, respectively. OHB reductase activity of (L)-lactate dehydrogenase A from Lactococcus lactis was increased by introducing the GIn85Cys point mutation into the active site of the enzyme. Simultaneous expression of the homoserine transaminase and OHB reductase enzymes in a homoserine-overproducing strain growing on glucose yielded $0.58 \mathrm{~g} / \mathrm{L} \mathrm{DHB}$ after $24 \mathrm{~h}$ shake flask cultivation. During a fed-batch cultivation of this strain $5.3 \mathrm{~g} / \mathrm{L} \mathrm{DHB}$ were produced from glucose at a molar yield of $0.1 \mathrm{~g} / \mathrm{g}$. 


\section{Materials and Methods}

\section{Strains and cultivation conditions}

All strains were derived from E. coli K-12 substr. MG1655. The mutant strains listed in Table 1 were constructed by the phage transduction method (Malke et al., 1992) using single gene deletion mutants of the Keio collection (Baba et al., 2006) as the donor strains. Gene deletions were verified by PCR using primers that hybridized upstream and downstream of the modified genomic locus (Table S1).

All shake flask cultivations including pre-cultures were carried out in M9 mineral medium (Walther et al., 2017) supplemented with $0.2 \mathrm{~g} / \mathrm{L}$ methionine and threonine to complement strain auxotrophies. Growth cultures for DHB production were carried out in $250 \mathrm{~mL}$ baffled shake flasks containing $30 \mathrm{~mL}$ medium. Cultures were inoculated at an initial $\mathrm{OD}_{600}$ of 0.2 from overnight precultures and expression of homoserine and DHB pathway enzymes was induced by the addition of 1 mM isopropyl $\beta$-D-1-thiogalactopyranoside (IPTG) when culture $\mathrm{OD}_{600}$ was approximately 0.6 . Growth and pre-cultures were incubated at $37^{\circ} \mathrm{C}$ on a rotary shaker (Infors Multitron) running at 200 rpm.

\section{Construction of expression vectors}

High fidelity polymerase PhusionTM (Finnzymes) was used in all PCRs. T4 DNA ligase (Fermentas or Biolabs) was used to ligate digested PCR products into the corresponding vectors. Ligation products were transformed into E. coli DH5a cells (NEB) using standard protocols. All constructed plasmids were isolated and shown by DNA sequencing to contain the correct sequences. All plasmids used in this study are listed in Table 2. 
Construction of vectors for protein expression and purification: The genes $E C-m d h, E C-I d h, E C$-tyrB, EC-aspC, EC-ilvE, and LL-IdhA, LL-panE were PCR-amplified from genomic DNA of E. coli K12-substr. MG1655, or of L. lactis subsp. lactis II1403, respectively, using the forward and reverse primers listed in Supplementary Table S1. The resulting DNA fragments were digested with the restriction enzymes listed in Supplementary Table S1 and ligated into the corresponding restriction sites of the pET28(a)+ vector (Novagen).

\section{Construction of vectors for expression of the homoserine and the DHB pathway:}

Plasmids pEXT20-aspC and pEXT20-LLIdh ${ }_{A Q 85 C}$ were constructed by amplifying the EC-aspC and $L L-I d h A_{Q 85 C}$ genes by PCR using the forward and reverse primer couples 609/610 and 679/680, respectively, that introduced a ribosome binding site (RBS) in front of each gene, and BamHI and Sall restriction sites upstream of the RBS and downstream of the stop codon, respectively. Genomic DNA of $E$. coli $\mathrm{K}-12$ substr. MG1655 or the pET28-LL-IdhA ${ }_{a 85 C}$ plasmid was used as the template. The PCR products were digested with $\mathrm{BamHI}$ and Sall, ligated into the corresponding sites of the pEXT2O expression vector (Dykxhoorn et al., 1996).

Plasmid pEXT20-ilvE-LLIdhA $A_{Q 85 C}$ was constructed by PCR-amplifying the EC-ilvE and LL-IdhA $A_{Q 85 C}$ genes individually using the forward and reverse primer pairs $820 / 821$ and $822 / 823$, respectively, listed in Table S1, and pET28-ilvE or pET28-LLIdhA $A_{Q 85 C}$ as the template. The amplified PCR fragments were fused in an overlap extension PCR by adding $150 \mathrm{ng}$ of each fragment to $50 \mu \mathrm{L}$ of the reaction mix which contained primers 820 and 823 . The resulting PCR fragment was purified, digested with Kpnl and Xbal, and ligated into the corresponding sites of pEXT20.

Plasmid pEXT20-aspC-LLIdhA $A_{Q 85 c}$ was obtained by replacing the ilvE gene in pEXT20-ilvELLIdhA $_{\mathrm{Q} 85 \mathrm{C}}$ by aspC. Specifically, the $a s p C$ gene was amplified by PCR using the forward and reverse primers 668 and 674 (Table S1) that introduced a RBS in front of the gene, and Sacl and BamHI 


\section{ACCEPTED MANUSCRIPT}

restriction sites upstream of the RBS and downstream of the stop codon, respectively. pEXT20-aspC was used as the template. The Sacl/BamHI digested PCR fragment was ligated into the corresponding sites of the Sacl/BamHI-digested and gel-purified pEXT20-ilvE-LLIdh ${ }_{\mathrm{AQ} 85 \mathrm{C}}$ vector.

Plasmid pZA23-thrA was constructed by amplifying the E. coli thrA gene by PCR using the forward and reverse primers 1250 and 1252 that introduced a RBS in front of thrA, and EcoRI and Smal restriction sites upstream of the RBS and downstream of the stop codon, respectively. Genomic DNA from E. coli MG1655 was used as the template. The PCR product was digested with EcoRI and Smal, ligated into the corresponding sites of the pZA23 expression vector (Expressys ${ }^{\mathrm{TM}}{ }^{\text {). An aspartate }}$ kinase/homoserine dehydrogenase with strongly decreased sensitivity for inhibition by threonine was constructed by site directed mutagenesis which replaced serine in position 345 by phenylalanine (S345F). Site-directed mutagenesis was carried out as described above using the primers listed in Table S1. Plasmids created by PCR contained a new restriction site for Xhol which was introduced by silent mutation in addition to the functional mutation to facilitate identification of mutated clones.

Plasmid pZA23-thrA $\mathrm{A}_{5345 \mathrm{~F}}$-aspC-LLldhA $\mathrm{a}_{\mathrm{Q} 85 \mathrm{C}}$ was constructed by PCR-amplifying a DNA fragment containing the aspC-LL-IdhA $A_{Q 85 c}$ operon using pEXT20-aspC-LLIdhA $\mathrm{A}_{\mathrm{Q} 5 \mathrm{C}}$ as the template and forward and reverse primers $(1469,1479$, Table S1) which introduced Smal and Kpnl restriction sites upstream of $a s p C$ and downstream of $L L I d h_{A Q 85 C}$, respectively. The PCR product was digested with Smal and $K p n l$, ligated into the corresponding sites of the pZA23-thrA $\mathrm{A}_{5345}$ plasmid.

Site-directed mutagenesis of OHB reductase LL-LdhA $\mathrm{Q}_{\mathrm{Q} 5}$ : Point mutations to change the amino acid sequence of LL-LdhA were introduced by PCR (Phusion 1U, HF buffer $20 \%$ (v/v), dNTPs $0.2 \mathrm{mM}$, direct and reverse primers $0.04 \mu \mathrm{M}$ each, template plasmid $30-50 \mathrm{ng}$, water) using the oligonucleotide pair listed in Supplementary Table S1 and the pET28-LLIdhA plasmid as the template. The genes mutated by PCR contained a new restriction site listed in Supplementary Table S1 (introduced using silent mutations) in addition to the functional mutation to facilitate identification 


\section{ACCEPTED MANUSCRIPT}

of mutated clones. The PCR product was digested by $D p n l$ at $37^{\circ} \mathrm{C}$ for $1 \mathrm{~h}$ to remove template DNA, and transformed into competent E. coli DH5 $\alpha$ cells (NEB). Mutated plasmids were isolated from individual clones, and verified by restriction site analysis and DNA sequencing to carry the desired mutations.

\section{Protein expression and enzymatic assays}

Expression of enzymes: E. coli BL21 (DE3) star cells were transformed with the appropriate plasmids using standard genetic protocols (Sambrook et al., 1989). Enzymes with an $\mathrm{N}$-terminal hexa-His tag were expressed in $50 \mathrm{~mL}$ LB cultures that were inoculated from an overnight culture at $\mathrm{OD}_{600}$ of 0.1 and grown to $\mathrm{OD}_{600}$ of 0.6 before protein expression was induced by addition of $1 \mathrm{mM}$ IPTG to the culture medium. After $15 \mathrm{~h}$ of protein expression at $25{ }^{\circ} \mathrm{C}$, cells were harvested by centrifugation at $4000 \mathrm{~g}$ at $4{ }^{\circ} \mathrm{C}$ for $10 \mathrm{~min}$ and discarding the supernatant. Cell pellets were stored at $-20{ }^{\circ} \mathrm{C}$ until further analysis. Culture media contained $50 \mu \mathrm{g} / \mathrm{mL}$ kanamycin.

Purification of enzymes: Frozen cell pellets were suspended in $0.5 \mathrm{~mL}$ of breakage buffer $(50 \mathrm{mM}$ Hepes, $300 \mathrm{mM} \mathrm{NaCl}, \mathrm{pH}$ 7. 5) and broken open by four successive rounds of sonication (sonication interval: 20 s, power output: $30 \%$, sonicator: Bioblock Scientific, VibraCell ${ }^{\mathrm{TM}}$ 72437). Cell debris was removed by centrifuging the crude extracts for $15 \mathrm{~min}$ at $4{ }^{\circ} \mathrm{C}$ at $4000 \mathrm{~g}$ and retaining the clear supernatant. RNA and DNA were removed from the extracts by adding $15 \mathrm{mg} / \mathrm{mL}$ streptomycin sulfate (Sigma), centrifuging the samples at $13000 \mathrm{~g}$ for $10 \mathrm{~min}$ at $4{ }^{\circ} \mathrm{C}$ and retaining the supernatant. Clear protein extract was incubated for $1 \mathrm{~h}$ at $4{ }^{\circ} \mathrm{C}$ with $0.75 \mathrm{~mL}$ (bed volume) of Talon ${ }^{\mathrm{TM}}$ Cobalt affinity resin (Clontech). The suspension was centrifuged at $700 \mathrm{~g}$ in a table top centrifuge and supernatant was removed. The resin was washed with 10 bed volumes of wash buffer $(50 \mathrm{mM}$ Hepes, $300 \mathrm{mM} \mathrm{NaCl}, 15 \mathrm{mM}$ Imidazole, $\mathrm{pH}$ 7.5) before proteins were eluted with $0.5 \mathrm{~mL}$ of elution buffer (50 mM Hepes, $300 \mathrm{mM} \mathrm{NaCl}, 250 \mathrm{mM}$ Imidazole, pH 7.5). Purity of eluted enzymes was verified by SDS-PAGE analysis. Protein concentrations were estimated with the method of Bradford 


\section{ACCEPTED MANUSCRIPT}

(Bradford, 1976). To stabilize the lactate dehydrogenase enzymes, the elution buffer was systematically exchanged by $100 \mathrm{mM}$ phosphate buffer adjusted to $\mathrm{pH}$ 7. The protein sample was transferred to an Amicon ${ }^{\mathrm{TM}}$ Ultra centrifugal filter (cut-off $10 \mathrm{kDa}$ ), and centrifuged during $8 \mathrm{~min}$ at $4000 \mathrm{~g}$ at $4{ }^{\circ} \mathrm{C}$ to remove the buffer. The protein was diluted into phosphate buffer and the procedure was repeated 4 times.

Estimation of 2-oxo-acid reductase activities: The reaction mixture contained $60 \mathrm{mM}$ Hepes $(\mathrm{pH} 7)$, $50 \mathrm{mM}$ potassium chloride, $5 \mathrm{mM} \mathrm{MgCl}$, $0.25 \mathrm{mM} \mathrm{NADH}$, $(5 \mathrm{mM}$ fructose-1,6-bisphosphate with Ldh enzymes) (all products from Sigma), and appropriate amounts of purified enzymes or cell extract. Reactions were started by adding appropriate amounts of 2-oxo-4-hydroxybutyrate (OHB), pyruvate, or oxaloacetate (OAA). Enzymatic assays were carried out at $37^{\circ} \mathrm{C}$ in 96 -well flat bottomed microtiter plates in a final volume of $250 \mu \mathrm{L}$. The reactions were followed by the absorption of NADH at $340 \mathrm{~nm}$ in a microplate reader (BioRad 680XR). OHB was synthesized by incubating $125 \mathrm{mM}$ homoserine with snake venom (L)-amino acid oxidase (1.25 U/mL, Sigma) and catalase (4400 U/mL, Sigma) in $100 \mathrm{mM}$ Tris buffer at $\mathrm{pH} 7.8$ for $90 \mathrm{~min}$ at $37{ }^{\circ} \mathrm{C}$. Subsequently, the reaction mixture was purified on an Amicon ${ }^{\mathrm{TM}}$ Ultra centrifugal filter with a cut-off of $10 \mathrm{kDa}$ to eliminate the enzymes (method adapted from (Wellner and Lichtenberg, 1971)). OHB was quantified by mixing $100 \mu \mathrm{L}$ of the tested solution with $1 \mathrm{~mL}$ of a solution containing $1 \mathrm{M}$ sodium arsenate and $1 \mathrm{M}$ boric acid at $\mathrm{pH}$ 6.5. The mixture was incubated at room temperature for $30 \mathrm{~min}$ and the absorbance at $325 \mathrm{~nm}$ was used to quantify OHB. The relation between absorbance and concentration of the ketone was calibrated using pyruvate solutions of known concentrations (method adapted from (Wellner and Lichtenberg, 1971)). The typical OHB yield of the method was $90 \%$.

Estimation of transaminase activities: Transaminase activity of several candidate aminotransferases on their preferred substrate and homoserine was quantified with 2-oxoglutarate as the amino group acceptor. Reaction rates were measured by monitoring the NADH-dependent reduction of the 2- 


\section{ACCEPTED MANUSCRIPT}

oxoacid products of the transaminase reaction. The reaction mixture contained $60 \mathrm{mM}$ Hepes $(\mathrm{pH} 7)$, $50 \mathrm{mM}$ potassium chloride, $5 \mathrm{mM} \mathrm{MgCl}$, $4 \mathrm{mM}$ 2-oxoglutarate, $0.1 \mathrm{mM}$ pyridoxal-5'-phosphate (PLP), $0.25 \mathrm{mM} \mathrm{NADH,} \mathrm{(optionally} 5 \mathrm{mM}$ fructose-1,6-bisphosphate) (all products from Sigma), 4 Units/mL of auxiliary 2-hydroxyacid dehydrogenase, and appropriate amounts of purified aminotransferase or cell extract. The auxiliary dehydrogenase enzyme was purified PanE from $L$. lactis in case of the amino acids phenylalanine and leucine (Chambellon et al., 2009), malate dehydrogenase (Sigma) in case of aspartate, and rabbit muscle (L)-lactate dehydrogenase (Sigma) when homoserine was used as the starting substrate. Reactions were started by adding appropriate amounts of the amino acid. The assays were carried out at $37{ }^{\circ} \mathrm{C}$ in 96 -well flat bottomed microtiter plates in a final volume of $250 \mu \mathrm{L}$. NADH consumption was monitored in a microplate reader (BioRad 680XR).

\section{Analytical methods}

Quantification of glucose and metabolites was carried out by High Performance Liquid Chromatography (HPLC) on an Ultimate 3000 system (Thermo scientific, France) equipped with an autosampler (WPS-3000RS, Dionex), which was connected to a RI detector (RID 10A, Shimadzu), a UV/VIS detector (SPD-20A, Shimadzu), and/or a MSQ mass spectrometer (Finnigan Surveyor MSQ plus) depending on the measured compounds.

Sugars and organic acids were measured with the UV and RI detectors and by using a cationexchange column (Aminex HPX-87H - $300 \times 7.8 \mathrm{~mm}, 9 \mu \mathrm{m}$, protected by a "Micro-Guard cation H Refill Cartridge" precolumn, Biorad). Mobile phase was $1.25 \mathrm{mM} \mathrm{H}_{2} \mathrm{SO}_{4}$ at a flow rate of $0.5 \mathrm{ml} / \mathrm{min}$. Column temperature was held at $35{ }^{\circ} \mathrm{C}$. Homoserine, methionine and threonine concentrations were determined on the RI detector and by using a Chirex 3126 column (Phenomenex) with an aqueous mobile phase containing $2 \mathrm{mM}$ CuSO4 and $15 \%$ methanol. Flow rate was $1 \mathrm{ml} / \mathrm{min}$. The column was held at $22^{\circ} \mathrm{C}$. DHB concentrations were measured using an Aminex HPX-87H column (protected by a 


\section{ACCEPTED MANUSCRIPT}

"Micro-Guard cation H Refill Cartridge" precolumn) held at $48{ }^{\circ} \mathrm{C}$. Mobile phase was $0.01 \%$ (v/v) formic acid at $0.4 \mathrm{ml} / \mathrm{min}$ isocratic flow rate. Depending on the concentration range, detection and quantification of DHB were performed by a dual-wave UV-VIS (200 nm and $210 \mathrm{~nm}$ ) detector (Dionex Diode Array Detector) or by a MSQ mass spectrometer in electrospray mode (ESI probe at $0.25 \mathrm{kV}$ ) with negative ionization (ionization temperature, $450^{\circ} \mathrm{C}$; cone voltage, 50 volts).

Exhaust gas of the bioreactor culture was analyzed by a Thermo Scientific Prima Pro mass spectrometer. Total Organic Carbon (TOC) was measured using a Shimadzu TOC-L analyzer with ASI-L auto sampler. Preparation of standard solutions was made with potassium hydrogen phthalate (28420-82, Nacalai Tesque Inc). TOC of a sample was calculated from three replicate measurements.

\section{Bioreactor cultures}

The pre-cultures for the inoculation of the bioreactors were cultivated in $1000 \mathrm{~mL}$ shake flasks containing $150 \mathrm{~mL}$ mineral medium (composition as indicated above) until exponential phase. The cells were harvested and used to inoculate a $2 \mathrm{~L}$ bioreactor (Biostat B Sartorius) that initially contained $1500 \mathrm{~mL}$ medium adjusting an $\mathrm{OD}_{600}$ of $\sim 0.3$. The composition of the fermentation medium was similar to the mineral medium used in the shake flask experiments, except that it additionally contained $6 \mathrm{~g} / \mathrm{l}\left(\mathrm{NH}_{4}\right)_{2} \mathrm{HPO}_{4}, 0.4 \mathrm{~g} / \mathrm{l}\left(\mathrm{NH}_{4}\right)_{2} \mathrm{SO}_{4}, 1 \mathrm{~g} / \mathrm{L}$ threonine and methionine, $6 \mathrm{~g} / \mathrm{L}$ citrate and no MOPS. Initial glucose concentration was $45 \mathrm{~g} / \mathrm{L}$. Glucose concentration was monitored during the fermentation and a concentrated glucose stock solution (500 g/L) was manually added to assure nonlimiting glucose concentrations during the first $45 \mathrm{~h}$ of cultivation. The $\mathrm{pH}$ of the cultures was kept at 7.0 by the addition of $5 \mathrm{M} \mathrm{KOH}$, and reactors were aerated with air at 0.3 to 1.5 vvm. Dissolved oxygen tension was maintained above $30 \%$ of the saturating oxygen concentration by adjusting the appropriate agitation speed (300-1500 rpm, Rushton rotor, $28 \mathrm{~mm}$ diameter) and aeration rate. Polypropylene glycol (P 2,000) was used as antifoaming agent during the culture. 


\section{Results}

\section{Identification of enzymes with OHB reductase and homoserine transaminase activity}

We first set out to identify enzymes with homoserine transaminase activity. It has been previously reported that transaminases frequently have significant activity on sterically and electrostatically different substrates, which explains that alternative transaminases could take over the metabolic function of a deleted transaminase enzyme (Berg et al., 1988; Jensen and Calhoun, 1981). We intended to make use of this pronounced promiscuity of transaminases and characterized enzymes from three different classes of aminotransferases, namely the aspartate (EC-AspC), phenylalanine (EC-TyrB), and branched-chain amino acid (EC-IlvE) transaminases of E. coli on homoserine and their corresponding preferred substrate. The genes encoding these enzymes were amplified from genomic DNA and cloned into the pET-28(a)+ expression vector. The His-tagged enzymes were expressed in E. coli BL21(DE3) cells, and purified using affinity chromatography. The purity of the purified protein fraction was verified by SDS-PAGE (not shown) prior to enzymatic tests.

The estimated $\mathrm{Km}$ values of the three aminotransferases EC-AspC, EC-IlvE and EC-TyrB for their respective natural substrates aspartate, leucine, and phenylalanine were very similar to previously reported results (Lee-Peng et al., 1979; Mavrides and Orr, 1975; Yano et al., 1998) (Table 3) indicating that our assay conditions were appropriate for the characterization of these enzymes. The three tested transaminases had only residual activity on homoserine which was at least more than 450 -fold lower than on their natural substrate (Table 3). Initial reaction velocities of the enzymes on homoserine did not saturate at substrate concentrations of up to $50 \mathrm{mM}$, which was an additional indicator for their comparatively poor activity on homoserine. Since EC-AspC had the highest activity on homoserine with $0.082 \mu \mathrm{mol} /\left(\mathrm{mg}_{\text {prot }} \mathrm{min}\right)$ we chose this enzyme for the implementation of the synthetic homoserine-DHB pathway. 


\section{ACCEPTED MANUSCRIPT}

We continued our work with the identification of enzymes with 2-oxo-4-hydroxybutyrate (OHB) reductase activity. Our screen comprised four 2-hydroxy acid dehydrogenases which are active on substrates that are sterically cognate to OHB. Specifically, we estimated the kinetic parameters of lactate dehydrogenase (Ldh), malate dehydrogenase, and branched-chain 2-hydroxyacid dehydrogenase enzymes on OHB and their natural substrates. The selected enzymes included (L)-Ldh from Lactococcus lactis, which is encoded by LL-IdhA (Llanos et al., 1992), (D)-Ldh from E. coli, which is encoded by EC-IdhA (Bunch et al., 1997), (L)-malate dehydrogenase from E. coli, which is encoded by EC-mdh (Sutherland and McAlister-Henn, 1985), and the branched-chain 2-hydroxyacid dehydrogenase from L. lactis, which is encoded by LL-panE (Chambellon et al., 2009). As for the characterization of the aminotransferases, the genes encoding these enzymes were cloned into $\mathrm{PET}$ 28(a)+ expression vectors, and the His-tagged proteins were expressed and purified to homogeneity prior to enzymatic assays.

High OHB reductase activity of $11 \mu \mathrm{mol} /\left(\mathrm{mg}_{\text {prot }} \mathrm{min}\right.$ ) was found for LL-LdhA (Table 4), which was in qualitative agreement with an earlier work reporting OHB reductase activity for rabbit muscle (L)-lactate dehydrogenase (Lane and Dekker, 1969). Our results showed furthermore that the (D)lactate dehydrogenase EC-Ldh $\left(0.56 \mu \mathrm{mol} /\left(\mathrm{mg}_{\text {prot }} \mathrm{min}\right)\right)$ and the branched chain 2-hydroxyacid dehydrogenase LL-PanE $\left(2.07 \mu \mathrm{mol} /\left(\mathrm{mg}_{\text {prot }} \min \right)\right)$ were also active on OHB. In contrast, the EC-Mdh enzyme had only hardly measurable activity on OHB (Table 4). Substrate affinities of the enzymes for OHB could not be estimated since initial reaction velocities did not saturate at substrate concentrations of up to $20 \mathrm{mM}$ OHB. Therefore, we used the ratio of the reaction rates attained at saturating concentrations of the natural substrate or at $20 \mathrm{mM} \mathrm{OHB}$ as a rough estimate for the substrate specificities of the enzymes. We found that LL-LdhA had not only the highest activity on $\mathrm{OHB}$, but also the smallest specificity for its natural substrate (Table 4). Therefore, we decided to continue our work with this enzyme. 


\section{ACCEPTED MANUSCRIPT}

\section{Engineering of (L)-lactate dehydrogenase to improve OHB reductase activity}

Key amino acid residues that provide substrate specificity to LL-IdhA were identified by protein sequence alignment of several (L)-lactate dehydrogenases of different biological origin, and visual inspection of a previously published crystal structure from Geobacillus stearothermophilus bound to its activator fructose-1,6-bisphosphate, the NAD cofactor, and the substrate analogue oxamate (Wigley et al., 1992). Figure 2 shows key residues in the active site of GS-Ldh. The negative charge of the substrate carboxylic acid group is neutralized by electrostatic interaction with the positively charged side chain of Arg155. Thr233 and Asn126 contribute to correct substrate positioning by undergoing additional polar interactions with the oxamate carboxyl and oxo functions, and $\mathrm{Gln} 86$ restricts the size of the active site pocket. The catalytic residues His179 and Arg92 serve as the acid/base catalyst and to stabilize the developing charge, respectively, during product formation. The pivotal role of these residues in substrate binding and catalysis has been reported in previous studies ((Dunn et al., 1991) and references therein).

Manual docking of OHB into the active site configuration of Gs-Ldh revealed a steric clash between Gln86 (which aligns to Gln85 in LL-LdhA) and the larger synthetic substrate (Figure 2). Therefore, the impact of mutations in position GIn85 on OHB reductase activity was characterized. Out of the 19 alternative amino acid residues assayed in position 85, only cysteine and asparagine significantly increased OHB reductase activity (not shown). In a refined analysis of both mutants we found that the best variant LL-LdhA GIn85Cys had a 4-fold increased activity on OHB and a more than 4.5-fold decreased activity on the natural substrate pyruvate (Table 5). Contrary to the wild-type enzyme, the Gln85Cys mutant was not saturated by pyruvate concentrations of up to $20 \mathrm{mM}$ thus exhibiting an almost equal affinity for both substrates (Table 5). Therefore, the LL-LdhA $A_{a 85 c}$ mutant enzyme was used as the OHB reductase in the synthetic DHB pathway. 


\section{ACCEPTED MANUSCRIPT}

\section{Optimization of DHB production by engineered $E$. coli}

To achieve high DHB production via the above described synthetic pathway, both homoserine production and homoserine-to-DHB conversion needed to be optimized. Homoserine production was increased by expressing the threonine-insensitive bifunctional aspartate kinase/homoserine dehydrogenase mutant, $\operatorname{Thr}_{\mathrm{S345F}}$, from a medium-copy plasmid. To further increase homoserine availability in the production strain, the homoserine-consuming homoserine kinase and homoserine O-succinyltransferase enzymes, which are encoded by thrB and metA, respectively, were deleted. The soluble lactate dehydrogenase of E. coli, which is encoded by EC-IdhA and which also bears some OHB reductase activity (Table 4), was deleted from the genome of the production strain to properly demonstrate the positive contribution of the optimized OHB reductase enzyme LL-LdhA $\mathrm{A}_{Q 85 \mathrm{C}}$ to DHB production. In addition, alcohol dehydrogenase, encoded by adhE, was deleted to increase DHB production under oxygen-limited conditions (not shown in this paper).

The resulting quadruple mutant E. coli $\triangle a d h E \Delta l d h A \Delta t h r B \Delta m e t A$ (strain Eco4) was transformed with plasmids that expressed $\mathrm{ThrA}_{\mathrm{S345F}}$, the homoserine transaminase-bearing EC-AspC, and the OHB reductase LL-LdhA $A_{Q 85 C}$ alone or in combination. DHB and homoserine production by these strains were determined after $24 \mathrm{~h}$ of cultivation under aerobic conditions on a defined mineral medium which contained $20 \mathrm{~g} / \mathrm{L}$ glucose as the carbon source and which was supplemented with $0.5 \mathrm{~g} / \mathrm{L}$ methionine and threonine to complement the auxotrophies of the strains. Strain Eco4 which harbored no plasmids produced $477 \mathrm{mg} / \mathrm{L}$ homoserine indicating that the deletion of metA and thrB effectively blocked homoserine consumption by the methionine and threonine pathways (Table 6). The production of $59 \mathrm{mg} / \mathrm{L} \mathrm{DHB}$ by strain Eco4 showed that E. coli possesses residual endogenous homoserine transaminase and OHB reductase activities which lead to the production of small amounts of DHB under conditions where homoserine was overproduced. The transformation of empty control plasmids into Eco4 yielded strains Eco5-7 which exhibited impaired growth and reduced homoserine and DHB production (Table 6) indicating that these plasmids represent a significant metabolic burden. 


\section{ACCEPTED MANUSCRIPT}

Strain Eco10 expressed both DHB pathway enzymes EC-AspC and LL-IdhA $A_{Q 85 C}$ but had no increased ThrA $\mathrm{S}_{5345 \mathrm{~F}}$ activity. Although growth of the strain was restored, it only produced $48 \mathrm{mg} / \mathrm{L}$ DHB and $329 \mathrm{mg} / \mathrm{L}$ homoserine which was less than the Eco4 strain. Similarly, strain Eco10 which expressed ThrA $\mathrm{A}_{s 345}$ but no DHB pathway enzyme produced only $48 \mathrm{mg} / \mathrm{L}$ DHB and thus less than Eco4. In contrast, strains Eco11 and Eco12, which expressed EC-AspC or LL-LdhA $A_{Q 85 C}$ in addition to ThrA $\mathrm{S}_{\mathrm{S} 35 \mathrm{~F}}$, exhibited approximately 2 -fold increased DHB production when compared to Eco4 and Eco10. As expected, DHB production was further increased to $190 \mathrm{mg} / \mathrm{L}$ when both DHB pathway enzymes, EC-AspC and LL-LdhA ${ }_{Q 85 C}$, were expressed simultaneously with $\operatorname{ThrA}_{5345 F}$ in strain Eco13. Taken together, these results showed that each individual enzyme of the synthetic DHB pathway positively contributed to DHB production (compare Eco10, 11, 12, 13), and that increased homoserine production was required to achieve significant DHB titers (compare Eco13 and Eco9, Table 6). To further optimize DHB production we decreased the metabolic burden on the strain by expressing $T_{h r} A_{s 345 F}$ and the two DHB pathway enzymes from the same medium-copy number plasmid. DHB production by the resulting strain Eco18 was increased to $410 \mathrm{mg} / \mathrm{L}$ (Table 6).

\section{Fed-batch cultivation of DHB-producing strain}

DHB production by strain Eco19 was analyzed in a fed-batch bioreactor cultivation. The strain was grown on the same mineral medium as during the shake flask experiments except that the medium was not buffered by MOPS, ammonium (and phosphate) concentrations were increased by the addition of $6 \mathrm{~g} / \mathrm{L}$ diammonium phosphate, initial threonine and methionine concentrations were increased to $1 \mathrm{~g} / \mathrm{L}$, and $6 \mathrm{~g} / \mathrm{L}$ citrate were added to stabilize the iron ions in the medium. HPLC analyses confirmed that citrate was not consumed during the cultivation. Controlled addition of $\mathrm{KOH}$ was used to maintain the culture medium at $\mathrm{pH} 7$. Glucose concentration was monitored throughout the fermentation, and a concentrated glucose stock solution was manually added to the reactor to 


\section{ACCEPTED MANUSCRIPT}

assure non-limiting carbon source concentrations during the entire cultivation. The dissolved oxygen concentration was maintained above $40 \%$ of the saturating concentration to assure aerobic conditions.

Under these conditions, strain Eco19 ceased exponential growth after approximately $9 \mathrm{~h}$ of cultivation due to the depletion of threonine in the culture medium (Figure 2). The onset of DHB production coincided with the growth arrest. The strain continued to consume glucose during the following $39 \mathrm{~h}$ of cultivation and DHB concentration increased linearly up to a final concentration of approximately $5.3 \mathrm{~g} / \mathrm{L}$ corresponding to a product yield of $0.1 \mathrm{~g} / \mathrm{g}$. Interestingly, homoserine concentration peaked at only $0.3 \mathrm{~g} / \mathrm{L}$ at the end of the exponential growth phase and decreased during the DHB production phase indicating that the amino acid was directly converted into DHB (Figure 2).

A carbon balance of the fed-batch fermentation revealed that only $59 \%$ of the consumed carbon could be recovered in the form of biomass $(9 \%)$, soluble fermentation products identified by HPLC (11\%), and $\mathrm{CO}_{2}(39 \%)$ (Table 7). In an attempt to identify unknown carbon sinks we measured the Total Organic Carbon (TOC) content of the fermentation medium after $48 \mathrm{~h}$ with and without cells and compared these results with our HPLC analyses and spectrophotometric biomass measurements. We found that $0.8 \mathrm{C}-\mathrm{mol}$ in the medium could not be accounted for by HPLC analyses (Table S2, Please note that concentrations of OHB and lysine were found to be zero.). Since TOC and spectrophotometric measurements of the biomass-bound carbon gave identical results (0.3 C-mol, Table S2), we concluded that the apparent lack of carbon could not be explained by unexpected alterations of the biomass composition.

When the carbon balance was complemented by TOC measurements, $86 \%$ of the total consumed carbon could be recovered (Table 7). From these results we conclude that $27 \%$ of the total consumed carbon were bound in one or several unidentified products which have accumulated 


\section{ACCEPTED MANUSCRIPT}

in the medium as the result of unexpected metabolic activities and/or cell lysis, and that $14 \%$ of the carbon most likely left the system in the form of one or several unidentified volatile products. 


\section{ACCEPTED MANUSCRIPT}

\section{Discussion}

Direct cost-efficient microbial synthesis of methionine or its analogue HMTB from sugar is hampered by both the high metabolic cost of sulfur incorporation (Kromer et al., 2006) and the comparatively low solubility of methionine which limits product concentrations at physiological temperatures and near neutral $\mathrm{pH}$ to approximately $50 \mathrm{~g} / \mathrm{L}$ (Fuchs et al., 2006). To tackle these technological problems, we have recently proposed a two-stage process which includes the fermentative production of DHB from sugar (Walther et al., 2017), and the subsequent carbonconserving chemical incorporation of methanethiol to produce HMTB (Deck et al., 2009). In contrast to the method described by Shim and coworkers (Shim et al., 2016), where methionine is enzymatically produced from the activated precursors O-acetylhomoserine or O-succinylhomoserine, the DHB-based process, at least in theory, does not generate any metabolic by-products and eventually yields the water soluble methionine analogue HMTB thus permitting high product titers.

Since annotated DHB-producing metabolic pathways do not exist, we and others have recently conceived three-step synthetic metabolic pathways which produce DHB from malate (Li et al., 2014; Walther et al., 2013, 2017). By describing a pathway which derives DHB from homoserine in the present work, we extend the panel of DHB-producing metabolic routes. The synthetic pathway is composed of homoserine transaminase and $\mathrm{OHB}$ reductase activities, both of which have been identified in several natural transaminase or 2-hydroxyacid dehydrogenase enzymes, respectively. Among the tested enzymes, OHB reductase activity was found to be highest in (L)-LdhA from L. lactis. Activity of LL-LdhA on OHB was further enhanced by structure-based engineering of the enzyme, which alleviated a steric clash between the OHB substrate and Gln85 which restricts the size of the active pocket. Mutation of Gln85 to the smaller cysteine yielded an enzyme which accepted OHB and the natural substrate pyruvate with almost equal specificity thus supporting efficient OHB to DHB conversion. In contrast, homoserine transaminase activities of the tested enzymes were rather small compared to the preferred substrates. Nevertheless, we found that expression of the EC-AspC 


\section{ACCEPTED MANUSCRIPT}

enzyme which bears homoserine transaminase activity significantly increased DHB production suggesting that intracellular homoserine concentrations were sufficiently high to compete with the natural substrate aspartate.

A homoserine-overproducing $E$. coli strain which expressed the homoserine transaminase and $\mathrm{OHB}$ reductase enzymes $\mathrm{EC}-\mathrm{AspC}$ and $\mathrm{LL}-\mathrm{LdhA}_{\mathrm{Q} 85 \mathrm{C}}$, respectively, produced $5.3 \mathrm{~g} / \mathrm{L} \mathrm{DHB}$ at a yield of $0.1 \mathrm{~g} / \mathrm{g}$ after $48 \mathrm{~h}$ fed-batch cultivation. This result shows that significant DHB production can be achieved via the synthetic pathway. However, much work is necessary to reach industrially relevant productivities and yields. The development of more efficient enzymes represents the major lever to increase the performance of the homoserine-dependent DHB pathway. In particular, the very small activities of all tested transaminases on homoserine appear to limit pathway flux. It is therefore interesting that Bouzon and coworkers have very recently shown that the alanine aminotransferase double mutant AlaC A142P:Y275D has strongly increased activity on homoserine (Bouzon et al., 2017). These authors used long-term cultivations of $E$. coli cells under conditions that were selective for homoserine transaminase activity and subsequent genetic analysis of fast growing cells to obtain the new activity. The AlaC A142P:Y275D mutant enzyme was shown to have a $\mathrm{Km}$ of $1.7 \mathrm{mM}$ for homoserine (Bouzon et al., 2017), which makes it an attractive candidate to improve the performance of the synthetic DHB pathway. In addition, substrate affinity of the OHB reductase enzyme, which currently cannot be saturated by OHB concentrations of up to $20 \mathrm{mM}$, needs to be strongly improved. The intracellular OHB concentration is expected to be in the sub-millimolar range since the mass action ratio of aminotransferase reactions which use 2-oxoglutarate or pyruvate as amino group acceptor is commonly close to unity (Jankowski et al., 2008), and because the concentrations of the corresponding substrate/product couple 2-oxoglutarate (or pyruvate)/glutamate in E. coli are typically in the range of $0.4 \mathrm{mM}$ and $90 \mathrm{mM}$ (Bennett et al., 2008), respectively. Thus, only an OHB reductase enzyme with very high substrate affinity can "pull" carbon flux through the homoserine transaminase reaction thereby enabling efficient in vivo operation of the DHB pathway. 


\section{ACCEPTED MANUSCRIPT}

The optimization of the producer strain is another important factor to increase DHB yields.

Notably, strain auxotrophies for methionine and threonine which were caused by the deletions of MetA and ThrB should be removed in an industrial strain. This could be achieved, for instance, by decreasing the transcription of the corresponding genes rather than by deleting them. Furthermore, improving homoserine production appears to be a promising approach to increase DHB production, as shown for other homoserine-derived products like threonine and O-succinylhomoserine (Debabov, 2003; Hong et al., 2014; Lee et al., 2007). In this context, the results of Li et al. (2016) are particularly interesting in that they have demonstrated production of $40 \mathrm{~g} / \mathrm{L}$ by an engineered $E$. coli strain. Their initial strain harbored the same effective homoserine-enhancing deletions $(\Delta m e t A$, $\Delta t h r B)$ as our strain and overexpressed a bifunctional aspartate kinase/homoserine dehydrogenase (MetL). This strain produced only $6.8 \mathrm{~g} / \mathrm{L}$ homoserine at a yield of $0.13 \mathrm{~g} / \mathrm{g}$ from glucose after $48 \mathrm{~h}$ of a fed-batch cultivation, which is very similar to the $5.3 \mathrm{~g} / \mathrm{L} \mathrm{DHB}$ and $0.1 \mathrm{~g} / \mathrm{g}$ product yield which have been produced by our strain. Li et al. (2016) reached much higher homoserine titers of $33.4 \mathrm{~g} / \mathrm{L}$ and $40 \mathrm{~g} / \mathrm{L}$ when the producer strain was further optimized by additionally overexpressing the homoserine-exporting permease RhtA, and by deleting the homoserine-importing permease $\mathrm{TdcC}$, respectively. From the observations that homoserine inhibits aspartate kinase activity in vitro, and that overexpression of RhtA decreases intracellular homoserine concentrations, Li et al. (2016) conclude that accumulation of intracellular homoserine strongly inhibits its own biosynthesis. In line with these arguments we suggest that elevated intracellular homoserine concentrations, which build up as a consequence of the very small homoserine transaminase activities, are a major cause for the rather limited production of DHB by our strain. Increasing the efficiency of the synthetic DHB pathway enzymes can be expected to decrease homoserine accumulation and is, therefore, required to prevent product-feedback inhibition on the homoserine-producing pathway. Furthermore, strain optimization must tackle the problem of the formation of unknown fermentation products. Strain Eco19 transformed $41 \%$ of the consumed carbon into unidentified soluble $(27 \%)$ and volatile (14 \%) 


\section{ACCEPTED MANUSCRIPT}

products. Identifying these carbon sinks and preventing the formation of these by-products is a major requirement to improve DHB production.

In summary, we have demonstrated DHB production at a yield of $0.1 \mathrm{~g} / \mathrm{g}$ via a two-step synthetic metabolic pathway which derives from homoserine. Further enzyme engineering to increase the catalytic capacity of the synthetic pathway, and strain engineering to avoid excessive accumulation of unknown products and to redirect carbon flux towards DHB synthesis are necessary to achieve industrially relevant DHB productivities and yields. 


\section{ACCEPTED MANUSCRIPT}

\section{Acknowledgements}

This work was supported in part by an industrial grant from Adisseo. The authors are grateful to Amélie Vax, Lucie Spina Ceren Alkim, Hélène Serrano-Bataille and Julie Fredonnet for technical assistance during this work. 


\section{References}

Baba, T., Ara, T., Hasegawa, M., Takai, Y., Okumura, Y., Baba, M., Datsenko, K.A., Tomita, M., Wanner, B.L., Mori, H., 2006. Construction of Escherichia coli K-12 in-frame, single-gene knockout mutants: the Keio collection. Mol. Syst. Biol. 2, 2006.0008.

Bennett, B.D., Yuan, J., Kimball, E.H., Rabinowitz, J.D., 2008. Absolute quantitation of intracellular metabolite concentrations by an isotope ratio-based approach. Nat Protoc 3, 1299-1311.

Berg, C.M., Wang, M.D., Vartak, N.B., Liu, L., 1988. Acquisition of new metabolic capabilities: multicopy suppression by cloned transaminase genes in Escherichia coli K-12. Gene 65, 195202.

Bouzon, M., Perret, A., Loreau, O., Delmas, V., Perchat, N., Weissenbach, J., Taran, F., Marlière, P., 2017. A Synthetic Alternative to Canonical One-Carbon Metabolism. ACS Synth. Biol. 6, 15201533.

Bradford, M.M., 1976. A rapid and sensitive method for the quantitation of microgram quantities of protein utilizing the principle of protein-dye binding. Anal. Biochem. 72, 248-254.

Bunch, P.K., Mat-Jan, F., Lee, N., Clark, D.P., 1997. The IdhA gene encoding the fermentative lactate dehydrogenase of Escherichia coli. Microbiol. Read. Engl. 143 ( Pt 1), 187-195.

Chambellon, E., Rijnen, L., Lorquet, F., Gitton, C., van Hylckama Vlieg, J.E.T., Wouters, J.A., Yvon, M., 2009. The D-2-hydroxyacid dehydrogenase incorrectly annotated PanE is the sole reduction system for branched-chain 2-keto acids in Lactococcus lactis. J. Bacteriol. 191, 873-881.

Cherepanov, P.P., Wackernagel, W., 1995. Gene disruption in Escherichia coli: TcR and KmR cassettes with the option of Flp-catalyzed excision of the antibiotic-resistance determinant. Gene 158, 9-14.

Debabov, V.G., 2003. The Threonine Story, in: Faurie, D.R., Thommel, D.J., Bathe, B., Debabov, V.G., Huebner, S., Ikeda, M., Kimura, E., Marx, A., Möckel, B., Mueller, U., Pfefferle, W. (Eds.), Microbial Production of L-Amino Acids, Advances in Biochemical Engineering/Biotechnology. Springer Berlin Heidelberg, pp. 113-136.

Deck, P., Exner, K.M., Buschhaus, B., 2009. Method for the Production of D,L-2-Hydroxy-4-Alkylthio Butyric Acid. US2009318715 (A1).

Dilger, R.N., Baker, D.H., 2007. DL-Methionine is as efficacious as L-methionine, but modest L-cystine excesses are anorexigenic in sulfur amino acid-deficient purified and practical-type diets fed to chicks. Poult. Sci. 86, 2367-2374.

Dunn, C.R., Wilks, H.M., Halsall, D.J., Atkinson, T., Clarke, A.R., Muirhead, H., Holbrook, J.J., 1991. Design and synthesis of new enzymes based on the lactate dehydrogenase framework. Philos. Trans. R. Soc. Lond. B. Biol. Sci. 332, 177-184.

Dykxhoorn, D.M., St Pierre, R., Linn, T., 1996. A set of compatible tac promoter expression vectors. Gene 177, 133-136.

Faurie, R., Thommel, J., Bathe, B., Debabov, V.G., Huebner, S., Ikeda, M., Kimura, E., Marx, A., Möckel, B., Mueller, U., Pfefferle, W., 2003. Microbial Production of I-Amino Acids., Advances in Biochemical Engineering/Biotechnology. Springer, Berlin, Heidelberg.

Feedinfo News Service [WWW Document], n.d. URL http://www.feedinfo.com/ (accessed 4.13.16).

Fuchs, D., Fischer, J., Tumakaka, F., Sadowski, G., 2006. Solubility of Amino Acids: Influence of the pH value and the Addition of Alcoholic Cosolvents on Aqueous Solubility. Ind. Eng. Chem. Res. 45, 6578-6584.

Hagopian, K., Ramsey, J.J., Weindruch, R., 2005. Serine utilization in mouse liver: Influence of caloric restriction and aging. FEBS Lett. 579, 2009-2013.

Hong, K.-K., Kim, J.H., Yoon, J.H., Park, H.-M., Choi, S.J., Song, G.H., Lee, J.C., Yang, Y.-L., Shin, H.K., Kim, J.N., Cho, K.H., Lee, J.H., 2014. O-Succinyl-L-homoserine-based C4-chemical production: succinic acid, homoserine lactone, $\gamma$-butyrolactone, $\gamma$-butyrolactone derivatives, and 1,4butanediol. J. Ind. Microbiol. Biotechnol. 41, 1517-1524. 


\section{ACCEPTED MANUSCRIPT}

Jankowski, M.D., Henry, C.S., Broadbelt, L.J., Hatzimanikatis, V., 2008. Group contribution method for thermodynamic analysis of complex metabolic networks. Biophys. J. 95, 1487-1499.

Jensen, R.A., Calhoun, D.H., 1981. Intracellular roles of microbial aminotransferases: overlap enzymes across different biochemical pathways. Crit. Rev. Microbiol. 8, 229-266.

Krömer, J.O., Wittmann, C., Schröder, H., Heinzle, E., 2006. Metabolic pathway analysis for rational design of L-methionine production by Escherichia coli and Corynebacterium glutamicum. Metab Eng 8, 353-69.

Lane, R.S., Dekker, E.E., 1969. 2-keto-4-hydroxybutyrate. Synthesis, chemical properties, and as a substrate for lactate dehydrogenase of rabbit muscle. Biochemistry (Mosc.) 8, 2958-2966.

Lee, K.H., Park, J.H., Kim, T.Y., Kim, H.U., Lee, S.Y., 2007. Systems metabolic engineering of Escherichia coli for L-threonine production. Mol. Syst. Biol. 3, 149.

Lee-Peng, F.C., Hermodson, M.A., Kohlhaw, G.B., 1979. Transaminase B from Escherichia coli: quaternary structure, amino-terminal sequence, substrate specificity, and absence of a separate valine-alpha-ketoglutarate activity. J. Bacteriol. 139, 339-345.

Leuchtenberger, W., Huthmacher, K., Drauz, K., 2005. Biotechnological production of amino acids and derivatives: current status and prospects. Appl. Microbiol. Biotechnol. 69, 1-8.

Li, H., Wang, B., Zhu, L., Cheng, S., Li, Y., Zhang, L., Ding, Z.Y., Gu, Z.H., Shi, G.Y., 2016. Metabolic engineering of Escherichia coli W3110 for L-homoserine production. Process Biochem. 51, 1973-1983.

Li, X., Cai, Z., Li, Y., Zhang, Y., 2014. Design and construction of a non-natural malate to 1,2,4butanetriol pathway creates possibility to produce 1,2,4-butanetriol from glucose. Sci. Rep. 4, 5541.

Llanos, R.M., Hillier, A.J., Davidson, B.E., 1992. Cloning, nucleotide sequence, expression, and chromosomal location of $l d h$, the gene encoding $L-(+)$-lactate dehydrogenase, from Lactococcus lactis. J. Bacteriol. 174, 6956-6964.

Lutz, R., Bujard, H., 1997. Independent and tight regulation of transcriptional units in Escherichia coli via the LacR/O, the TetR/O and AraC/I1-I2 regulatory elements. Nucleic Acids Res. 25, 12031210.

Malke, H., Jeffrey, H., Miller, A., 1992. A Short Course in Bacterial Genetics - A Laboratory Manual and Handbook for Escherichia coli and Related Bacteria. Cold Spring Harbor Laboratory Press, Cold Spring Harbor.

Mavrides, C., Orr, W., 1975. Multispecific aspartate and aromatic amino acid aminotransferases in Escherichia coli. J. Biol. Chem. 250, 4128-4133.

Sambrook, J., Fritsch, E.F., Maniatis, T., 1989. Molecular Cloning: A Laboratory Manual, 2nd ed. Cold Spring Harbor Laboratory Press, Cold Spring Harbor.

Sauer, N., Emrich, K., Piepho, H.-P., Lemme, A., Redshaw, M.S., Mosenthin, R., 2008. Meta-analysis of the relative efficiency of methionine-hydroxy-analogue-free-acid compared with DLmethionine in broilers using nonlinear mixed models. Poult. Sci. 87, 2023-2031.

Shim, J., Shin, Y., Lee, I., Kim, S.Y., 2016. L-Methionine Production. Adv. Biochem. Eng. Biotechnol.

Shinka, T., Inoue, Y., Ohse, M., Ito, A., Ohfu, M., Hirose, S., Kuhara, T., 2002. Rapid and sensitive detection of urinary 4-hydroxybutyric acid and its related compounds by gas chromatography-mass spectrometry in a patient with succinic semialdehyde dehydrogenase deficiency. J Chromatogr B Anal. Technol Biomed Life Sci 776, 57-63.

Snell, K., 1986. The Duality of Pathways for Serine Biosynthesis Is a Fallacy. Trends Biochem. Sci. 11, 241-243.

Sutherland, P., McAlister-Henn, L., 1985. Isolation and expression of the Escherichia coli gene encoding malate dehydrogenase. J. Bacteriol. 163, 1074-1079.

Walther, T., Dressaire, C., Cordier, H., Francois, J.-M., 2013. A Method of Production of 2,4Dihydroxybutyric Acid. WO2013160762 (A2).

Walther, T., Topham, C.M., Irague, R., Auriol, C., Baylac, A., Cordier, H., Dressaire, C., Lozano-Huguet, L., Tarrat, N., Martineau, N., Stodel, M., Malbert, Y., Maestracci, M., Huet, R., André, I., Remaud-Siméon, M., François, J.M., 2017. Construction of a synthetic metabolic pathway for 


\section{ACCEPTED MANUSCRIPT}

biosynthesis of the non-natural methionine precursor 2,4-dihydroxybutyric acid. Nat. Commun. 8, 15828.

Wellner, D., Lichtenberg, L.A., 1971. Assay of amino acid oxidase. Methods Enzymol. 17, Part B, 593596.

Wigley, D.B., Gamblin, S.J., Turkenburg, J.P., Dodson, E.J., Piontek, K., Muirhead, H., Holbrook, J.J., 1992. Structure of a ternary complex of an allosteric lactate dehydrogenase from Bacillus stearothermophilus at 2.5 A resolution. J. Mol. Biol. 223, 317-335.

Willke, T., 2014. Methionine production--a critical review. Appl. Microbiol. Biotechnol. 98, 98939914.

Yano, T., Oue, S., Kagamiyama, H., 1998. Directed evolution of an aspartate aminotransferase with new substrate specificities. Proc. Natl. Acad. Sci. U. S. A. 95, 5511-5515.

Zelder, O., Haefner, S., Herold, A., Klopprogge, C., Schröder, H., Yocum, R.R., Williams, M.K., 2009. Use of dimethyl disulfide for methionine production in microoragnisms. US2009281353 (A1). 


\section{Figure and Table Legends}

Table 1: Strains used in this study.

Table 2: Plasmids used in this study.

Table 3: Kinetic parameters of several transaminases on homoserine and their natural substrates.

Subtext: Data are presented as means \pm STDV calculated from at least three replicates. ${ }^{*}$ ) Natural substrates (each at 20 $\mathrm{mM})$ : Ec-IlvE- leucine, Ec-TyrB - phenylalanine, Ec-AspC - aspartate. $\left({ }^{* *}\right)$ activity was estimated at a homoserine concentration of $50 \mathrm{mM}$. ns - Not saturated at up to $50 \mathrm{mM}$ substrate concentration.

Table 4: Kinetic parameters of candidate $\alpha$-oxo acid reductases on 2-oxo-4-hydroxybutyrate and their natural substrates.

Subtext: Data are presented as means \pm STDV calculated from at least three replicates. $\left({ }^{*}\right)$ Ratio of activities measured on the natural substrate (at $20 \mathrm{mM}$ pyruvate or $0.05 \mathrm{mM}$ oxaloacetate) and $\mathrm{OHB}$ (at $20 \mathrm{mM}$ ). ns - not saturated at substrate concentrations of up to $20 \mathrm{mM}$. nc - not calculated. Natural substrates: Pyruvate for Ec-Ldh, LI-LdhA; Oxaloacetate for EcMdh.

Table 5: Impact of mutations in (L)-lactate dehydrogenase A from L. lactis on its activity on pyruvate and 2-oxo-4-hydroxybutyrate.

Subtext:Data are presented as means \pm STDV calculated from at least three replicates. $\left({ }^{*}\right)$ Ratio of activities measured on pyruvate and $\mathrm{OHB}$ at $20 \mathrm{mM}$ substrate concentration. Ns - not saturated at substrate concentrations of up to $20 \mathrm{mM}$. nc not calculated.

Table 6: Product formation by E. coli strains expressing the synthetic DHB pathway.

Subtext:

(1) wt - wild-type strain, $\Delta 4-\triangle a d h E \Delta l d h A \Delta t h r B \Delta m e t A$

(2) E. coli genes $a s p C$, and $t h r A_{S 345 F}$ encode aspartate aminotransferase, and bifunctional aspartate kinasehomoserine dehydrogenase enzymes, respectively. Serine 345 was replaced by phenylalanine to alleviate threonine inhibition of ThrA. The LlldhA gene is from Lactococcus lactis and encodes (L)-lactate dehydrogenase. In this enzyme variant, glutamine 85 was replaced by cysteine to increase OHB reductase activity.

(3) Data from a single experiment. 
Table 7: Carbon balance of the fed-batch fermentation of strain Eco19.

Figure 1: Synthetic metabolic pathway for production of 2,4-dihydroxybutyrate from homoserine. Synthetic reactions are shown in red, natural homoserine pathway reactions are shown in black. Names of the enzymes catalyzing reactions in the natural homoserine pathway are shown in blue. OHB - 2-oxo-4-hydroxybutyrate, DHB - 2,4-dihydroxybutyrate.

Figure 2: Active site region in the crystal structure of (L)-lactate dehydrogenase of $G$. stearothermophilus. The synthetic 2-oxo-4-hydroxybutyrate (OHB) substrate shown in green was manually docked into the experimental X-ray structure of the enzyme complex with NAD and the substrate analogue oxamate (PDB code: $1 \mathrm{LDN}$ ). Atoms of key amino acid residues and substrates are colored according to element type: carbon, grey; nitrogen, blue; oxygen, red. Polar interactions between the oxamate and enzyme amino acid residues are shown as dashed red lines. The overall structure is shown in pale brown.

Figure 3: Fermentation profile of the DHB-producing Eco18 strain. The strain was cultivated on defined mineral medium which was supplemented with $1 \mathrm{~g} / \mathrm{L}$ threonine and methionine to complement strain auxotrophies. Glucose was manually added to assure non-limiting carbon source concentrations of $>10 \mathrm{~g} / \mathrm{L}$ during the fermentation. 


\section{ACCEPTED MANUSCRIPT}<smiles>NC(CC(=O)O)C(=O)O</smiles>

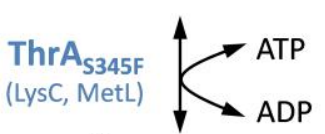<smiles>NC(CC(=O)O[Na])C(=O)O</smiles>

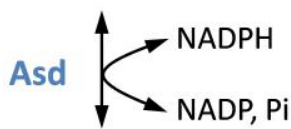<smiles>NC(CC=O)C(=O)O</smiles>

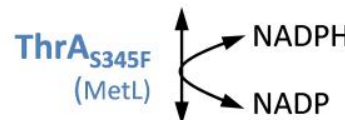

Homoserine transaminase EC-AspC

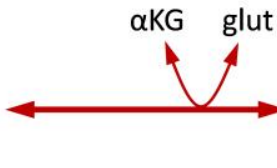

$\mathrm{OHB}$ reductase

LL-IdhAQ85C

NADH NAD<smiles>NC(CCO)C(=O)O</smiles><smiles>O=C(O)C(=O)CCO</smiles><smiles>C[13CH](C)[13CH]</smiles><smiles>O=C(O)C(O)CCO</smiles>

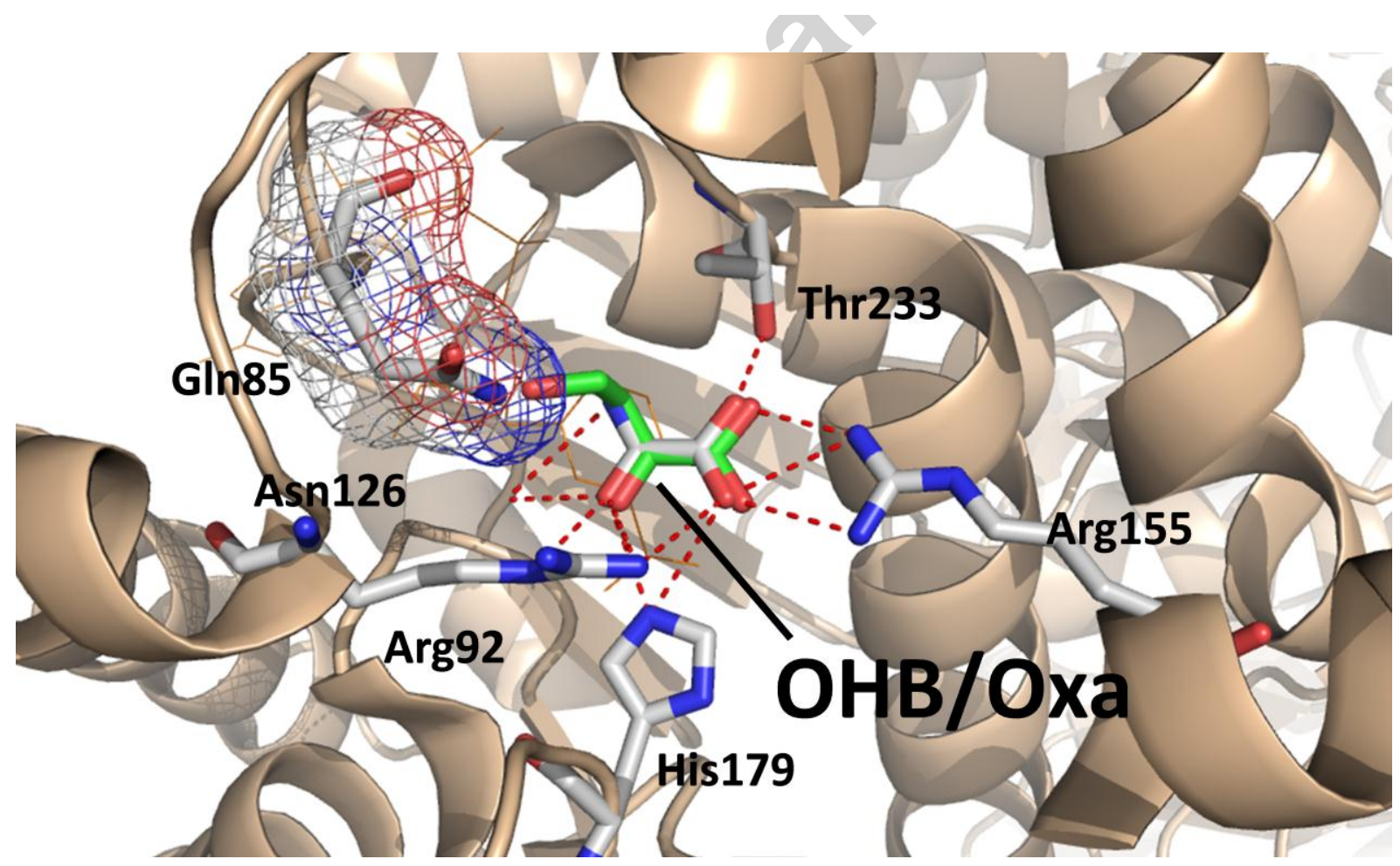




\section{ACCEPTED MANUSCRIPT}

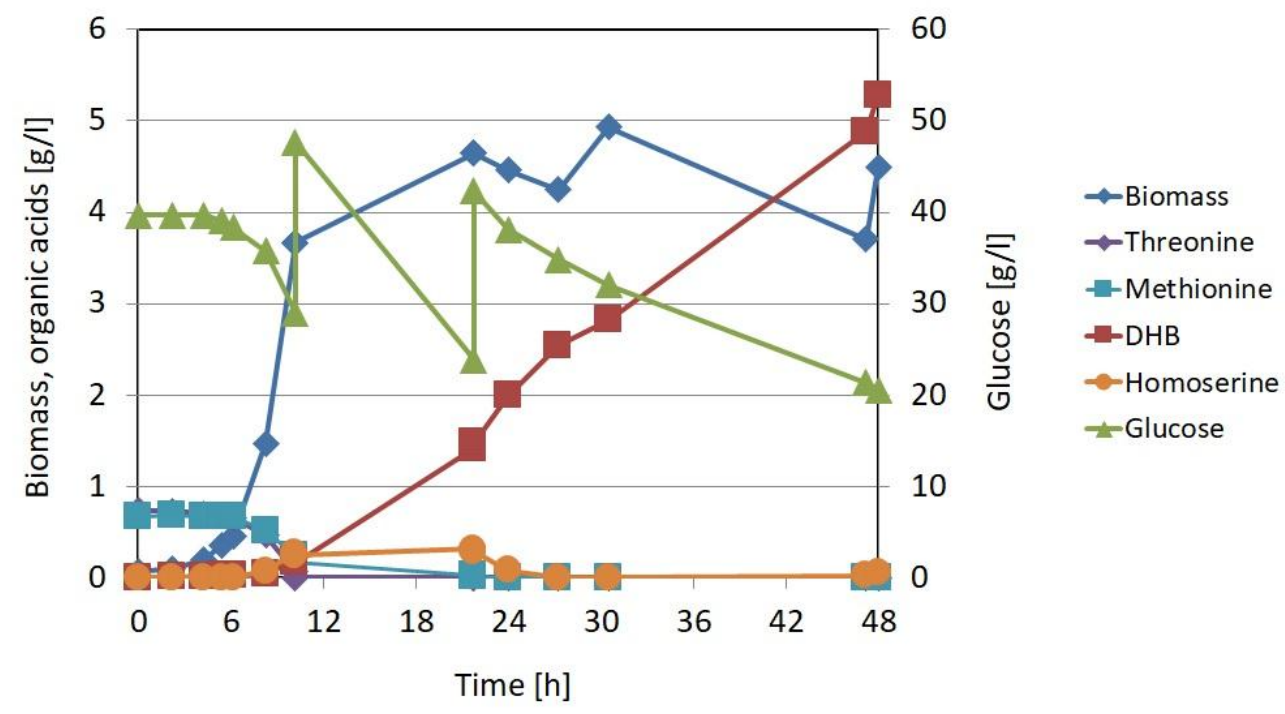

Table 1: Strains used in this study.

\begin{tabular}{|c|c|c|}
\hline Strain name & Genotype & Reference \\
\hline MG1655 & $F^{-} \lambda^{-}$ilvG- rfb-50 rph-1 & ATCC 47076 \\
\hline NEB5- $\alpha$ & $\begin{array}{l}\text { fhuA2 } \Delta(\text { argF-lacZ)U169 phoA glnV44 } Ф 80 \Delta \text { (IacZ)M15 gyrA96 recA1 } \\
\text { relA1 endA1 thi-1 hsdR17 }\end{array}$ & $\mathrm{NEB}^{\mathrm{TM}}$ \\
\hline BL21(DE3) & 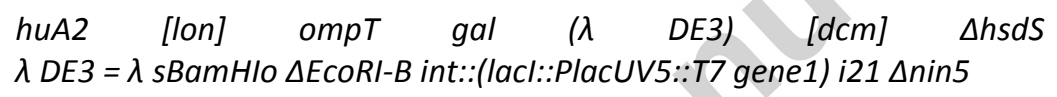 & $\mathrm{NEB}^{\mathrm{TM}}$ \\
\hline JW1228-1 & $\begin{array}{l}\mathrm{F}-, \Delta(\operatorname{araD}-\operatorname{araB}) 567, \Delta / a c Z 4787(:: \mathrm{rnB}-3), \lambda, r p h-1, \Delta(\text { rhaD-rhaB }) 568, \\
\text { hsdR51, } 4 \text { adhE748::kan }\end{array}$ & (Baba et al., 2006) \\
\hline JW1375-1 & $\begin{array}{l}\mathrm{F}-, \Delta(\operatorname{araD}-\operatorname{araB}) 567, \Delta / a c Z 4787(:: \mathrm{rrnB}-3), \lambda, \text { rph-1, } \Delta(\text { rhaD-rhaB }) 568, \\
\text { hsdR514, } \Delta \text { ldhA744::kan }\end{array}$ & (Baba et al., 2006) \\
\hline JW0002-3 & 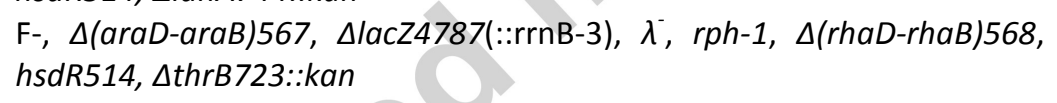 & (Baba et al., 2006) \\
\hline JW3973-1 & $\begin{array}{l}\text { F-, } \Delta(\operatorname{araD} \text {-araB)567, } \Delta l a c z 4787(:: r r n B-3), \lambda, r p h-1, \Delta(\text { rhaD-rhaB)568, } \\
\text { hsdR514, } \Delta \text { metA780::kan }\end{array}$ & (Baba et al., 2006) \\
\hline Eco4 & MG1655 $\triangle a d h E \Delta / d h A \Delta t h r B \Delta m e t A$ & This study \\
\hline Eco5 & Eco4 harboring empty pZA23 & This study \\
\hline Eco6 & Eco4 harboring empty pEXT20 & This study \\
\hline Eco7 & Eco4 harboring empty pZA23 and pEXT20 & This study \\
\hline Eco9 & Eco4 harboring empty pZA23 and pEXT20-aspC-LLldhA $\mathrm{a}_{\mathrm{Q} 5 \mathrm{C}}$ & This study \\
\hline Eco10 & Eco4 harboring pZA23-thr $A_{S 345 F}$ and empty pEXT20 & This study \\
\hline Eco11 & Eco4 harboring pZA23-thr $A_{s 345 F}$ and pEXT20-aspC & This study \\
\hline Eco12 & Eco4 harboring pZA23-thr $A_{5345 F}$ and pEXT20-LLldhA $A_{Q 85 C}$ & This study \\
\hline Eco13 & Eco4 harboring pZA23-thrA $\mathrm{A}_{\mathrm{S345F}}$ and pEXT20-aspC-LLldhA $\mathrm{A}_{\mathrm{Q} 55 \mathrm{C}}$ & This study \\
\hline Eco18 & Eco4 harboring pZA23-thrA $A_{S 345 F}$-aspC-LLIdhA $A_{Q 85 C}$ & This study \\
\hline
\end{tabular}


Table 2: Plasmids used in this study.

\begin{tabular}{|c|c|c|}
\hline Name & Relevant characteristics & Reference \\
\hline pCP20 & $\begin{array}{l}\text { ori } \mathrm{pSC} 101, \mathrm{Amp}^{\mathrm{R}} \text {, plasmid expressing Flp } \\
\text { recombinase to remove Kan cassette }\end{array}$ & $\begin{array}{l}\text { (Cherepanov } \\
\text { and }\end{array}$ \\
\hline pEXT20 & ori colE1, Amp ${ }^{\mathrm{R}}$, tac promoter & \\
\hline pZA23 & ori p15A, $\mathrm{Kan}^{\mathrm{R}}, \mathrm{P}_{\mathrm{A} 1 \mathrm{laco}-1}$ pro & $\begin{array}{l}\text { (Lutz and } \\
\text { Bujard, 1997) }\end{array}$ \\
\hline pET-28(a)+ & ori $\mathrm{f1}, \mathrm{Kan}^{\mathrm{R}}, \mathrm{T} 7$ promoter & Novagen $^{\mathrm{TM}}$ \\
\hline pZA23-thrA & pZA23 derivative carrying thrA & This study \\
\hline pZA23-thrA $A_{S 345 F}$ & pZA23 derivative carrying $t h r A_{S 345 F}$ & This study \\
\hline pEXT20-aspC & pEXT20 derivative carrying $a s p C$ & This study \\
\hline pEXT20-LLIdhA $A_{Q 85 C}$ & pEXT20 derivative carrying $L L / d h A_{Q 85 C}$ & This study \\
\hline pEXT20-aspC-LLIdhA $A_{a 85 c}$ & pEXT20 derivative carrying $a s p C$ and $\operatorname{LLIdhA_{a85C}}$ & This study \\
\hline pEXT20-ilvE-LLIdhA $A_{a 85 C}$ & pEXT20 derivative carrying ilvE and LLIdhA $A_{\mathrm{Q} 85 \mathrm{C}}$ & This study \\
\hline pZA23-thrA ${ }_{5345 F}$-aspC-LLIdhA $A_{Q 85 C}$ & $\begin{array}{l}\text { pZA23 derivative carrying } t h r A_{S 345 F} \text { aspC, } \\
\text { LLIdhA }_{a 85 C}\end{array}$ & This study \\
\hline
\end{tabular}

Table 3: Kinetic parameters of several transaminases on homoserine and their natural substrates.

\begin{tabular}{l|cc|cc}
\hline & \multicolumn{2}{|c|}{ Vmax $\left[\mu \mathrm{mol} /\left(\mathbf{m i n}^{*} \mathrm{mg}\right.\right.$ prot$\left.)\right]$} & \multicolumn{2}{c}{ Km [mM] } \\
\cline { 2 - 5 } Enzyme & Homoserine** & Natural substrate* & Homoserine & Natural substrate* \\
\hline Ec-llvE & $0.077 \pm 0.02$ & $35.5 \pm 3.2$ & $\mathrm{~ns}$ & $0.49 \pm 0.21$ \\
Ec-TyrB & $0.057 \pm 0.01$ & $86.4 \pm 2.8$ & $\mathrm{~ns}$ & $1.33 \pm 0.84$ \\
Ec-AspC & $0.082 \pm 0.01$ & $74.0 \pm 5.7$ & $\mathrm{~ns}$ & $1.59 \pm 0.69$ \\
\hline
\end{tabular}

Data are presented as means \pm STDV calculated from at least three replicates. $\left({ }^{*}\right)$ Natural substrates (each at $20 \mathrm{mM}$ ): EcIlvE- leucine, Ec-TyrB - phenylalanine, Ec-AspC - aspartate. $\left({ }^{* *}\right)$ activity was estimated at a homoserine concentration of 50 $\mathrm{mM}$. ns - Not saturated at up to $50 \mathrm{mM}$ substrate concentration. 
Table 4: Kinetic parameters of candidate $\alpha$-oxo acid reductases on 2-oxo-4-hydroxybutyrate and their natural substrates.

\begin{tabular}{|c|c|c|c|c|c|c|c|}
\hline \multirow[t]{2}{*}{ Enzyme } & \multicolumn{3}{|c|}{ Natural substrate } & \multicolumn{3}{|c|}{ 2-oxo-4-hydroxybutyrate } & \multirow[t]{2}{*}{ Specificity* } \\
\hline & $\begin{array}{c}V \max \\
{[\mu \mathrm{mol} /(\mathrm{mg}} \\
\min )]\end{array}$ & $\begin{array}{c}\mathrm{Km} \\
{[\mathrm{mM}]}\end{array}$ & Vmax/Km & $\begin{array}{c}\text { Vmax } \\
{[\mu \mathrm{mol} /(\mathrm{mg}} \\
\min )]\end{array}$ & $\begin{array}{c}\mathrm{Km} \\
{[\mathrm{mM}]}\end{array}$ & Vmax/Km & \\
\hline Ec-Ldh & $405 \pm 129$ & $2.86 \pm 0.47$ & 141 & $0.56 \pm 0.01$ & ns & nc & 718 \\
\hline LI-LdhA & $466 \pm 72$ & $1.39 \pm 0.2$ & 335 & $11.33 \pm 4.1$ & ns & nc & 41 \\
\hline Ec-Mdh & $105 \pm 22$ & $0.03 \pm 0.02$ & 3500 & $0.02 \pm 0.005$ & ns & nc & 4748 \\
\hline LI-PanE & - & - & - & $2.07 \pm 0.69$ & ns & nc & - \\
\hline
\end{tabular}

Data are presented as means \pm STDV calculated from at least three replicates. $\left({ }^{*}\right)$ Ratio of activities measured on the natural substrate (at $20 \mathrm{mM}$ pyruvate or $0.05 \mathrm{mM}$ oxaloacetate) and OHB (at $20 \mathrm{mM}$ ). ns - not saturated at substrate concentrations of up to $20 \mathrm{mM}$. nc - not calculated. Natural substrates: Pyruvate for Ec-Ldh, LI-LdhA; Oxaloacetate for EcMdh. 
Table 5: Impact of mutations in (L)-lactate dehydrogenase A from L. lactis on its activity on pyruvate and 2-oxo-4-hydroxybutyrate.

\begin{tabular}{|c|c|c|c|c|c|c|c|}
\hline \multirow[t]{2}{*}{ Mutation } & \multicolumn{3}{|c|}{ Pyruvate } & \multicolumn{3}{|c|}{ 2-oxo-4-hydroxybutyrate } & \multirow[t]{2}{*}{ Specificity* } \\
\hline & $\begin{array}{c}V \max \\
{[\mu \operatorname{mol} /(\mathrm{mg}} \\
\min )]\end{array}$ & $\begin{array}{c}\mathrm{Km} \\
{[\mathrm{mM}]}\end{array}$ & Vmax/Km & $\begin{array}{c}\text { Vmax } \\
{[\mu \mathrm{mol} /(\mathrm{mg}} \\
\min )]\end{array}$ & $\begin{array}{c}\mathrm{Km} \\
{[\mathrm{mM}]}\end{array}$ & Vmax/Km & \\
\hline$w t$ & $466 \pm 72$ & $1.39 \pm 0.2$ & 335 & $11 \pm 4$ & ns & $\mathrm{nc}$ & 41 \\
\hline Q85C & $101 \pm 11$ & ns & nc & $47 \pm 7$ & ns & nc & 2 \\
\hline Q85N & $216 \pm 29$ & ns & nc & $16 \pm 3$ & ns & nc & 13 \\
\hline
\end{tabular}

Data are presented as means \pm STDV calculated from at least three replicates. $\left({ }^{*}\right)$ Ratio of activities measured on pyruvate and $\mathrm{OHB}$ at $20 \mathrm{mM}$ substrate concentration. $\mathrm{Ns}-$ not saturated at substrate concentrations of up to $20 \mathrm{mM}$. nc $-\mathrm{not}$ calculated. 
Table 6: Product formation by E. coli strains expressing the synthetic DHB pathway.

\begin{tabular}{|c|c|c|c|c|c|c|}
\hline $\begin{array}{c}\text { Strain } \\
\text { No }\end{array}$ & $\begin{array}{c}\text { Strain } \\
\text { Genotype }^{(1)}\end{array}$ & Plasmids $^{(2)}$ & 20 & $\mathrm{OD}_{600}$ & $\begin{array}{c}\text { Homoserine } \\
{[\mathrm{mg} / \mathrm{L}]}\end{array}$ & $\begin{array}{r}\text { DHB 24h } \\
{[\mathrm{mg} / \mathrm{L}]}\end{array}$ \\
\hline MG1655 & wt & none & $y$ & $7.2 \pm 0.42$ & $0 \pm 0$ & $0 \pm 0$ \\
\hline Eco4 & $\Delta 4^{(1)}$ & none & & $5.6 \pm 0.45$ & $477 \pm 27$ & $59 \pm 4$ \\
\hline$E \cos 5^{(3)}$ & $\Delta 4$ & pZA23-empty & & 5.5 & 396 & 45 \\
\hline$E \operatorname{co} 6^{(3)}$ & $\Delta 4$ & 5 & pEXT20-empty & 1.6 & 36 & 11 \\
\hline Eco7 & $\Delta 4$ & pZA23-empty & + pEXT20-empty & & no growth & \\
\hline Eco9 & $\Delta 4$ & pZA23-empty & + pEXT20-aspC-LLIdhA $A_{Q 85 C}$ & $5.3 \pm 0.1$ & $329 \pm 5.8$ & $48 \pm 2$ \\
\hline $\mathrm{Eco1} 0^{(3)}$ & $\Delta 4$ & pZA23-thrA $A_{S 345 F}$ & + pEXT20-empty & 4.0 & 581 & 48 \\
\hline Eco11 & $\Delta 4$ & pZA23-thrA ${ }_{S 345 F}$ & + pEXT20-aspC & $6.1 \pm 0.1$ & $703 \pm 20$ & $87 \pm 8$ \\
\hline Eco12 & $\Delta 4$ & pZA23-thrA $A_{S 345 F}$ & + pEXT20-LLIdhA $A_{Q 85 C}$ & $5.5 \pm 0.1$ & $747 \pm 53$ & $81 \pm 1$ \\
\hline Eco13 & $\Delta 4$ & pZA23-thrA $A_{S 345 F}$ & $+p E X T 20$-aspC-LLIdhA $A_{Q 85 C}$ & $5.2 \pm 1$ & $1040 \pm 350$ & $190 \pm 17$ \\
\hline Eco18 & $\Delta 4$ & pZA23-thr $A_{5345 F^{-}}$ & spC-LLldhA $A_{085 C}$ & $5.4 \pm 0.1$ & $1110 \pm 12$ & $439 \pm 29$ \\
\hline
\end{tabular}

(4) wt - wild-type strain, $\triangle 4$ - $\triangle a d h E \Delta l d h A \Delta t h r B \Delta m e t A$

(5) E. coli genes $a s p C$, and $\operatorname{thr} A_{S 345 F}$ encode aspartate aminotransferase, and bifunctional aspartate kinasehomoserine dehydrogenase enzymes, respectively. Serine 345 was replaced by phenylalanine to alleviate 


\section{ACCEPTED MANUSCRIPT}

threonine inhibition of ThrA. The LlldhA gene is from Lactococcus lactis and encodes (L)-lactate dehydrogenase. In this enzyme variant, glutamine 85 was replaced by cysteine to increase OHB reductase activity.

(6) Data from a single experiment.

Table 7: Carbon balance of the fed-batch fermentation of strain Eco19.

\begin{tabular}{lcc}
\hline Compound & C-mol & \% Carbon \\
\hline Substrates & & \\
Glucose & 2.906 & \\
Thr & 0.037 & \\
Met & 0.034 & \\
Sum & $\mathbf{2 . 9 7 7}$ & $\mathbf{1 0 0}$ \\
\hline & & \\
Products & & \\
Biomass & 0.268 & 9.0 \\
DHB & 0.280 & 9.4 \\
Homoserine & 0.003 & 0.1 \\
Lactate & 0.030 & 1.0 \\
Acetate & 0.019 & 0.7 \\
CO & 1.149 & 38.6 \\
Sum & $\mathbf{1 . 7 4 9}$ & $\mathbf{5 9}$ \\
\hline & & \\
Undetected C in medium & 0.800 & 26.9 \\
Sum & $\mathbf{2 . 5 4 9}$ & $\mathbf{8 6}$ \\
\hline
\end{tabular}




\section{ACCEPTED MANUSCRIPT}

Highlights:

- A new synthetic metabolic pathway for production of 2,4-dihydroxybutyrate is presented

- The pathway employs homoserine transaminase and OHB reductase activities

- Homoserine transaminase activity was identified by screening of natural transaminases

- OHB reductase activity was improved by rational engineering of lactate dehydrogenase

- An engineered E. coli strain expressing the pathway produces DHB at a yield of $0.1 \mathrm{~g} / \mathrm{g}$ 